\title{
Dinâmicas culturais e educação: apropriação e (re) significação de espaços escolares por adolescentes
}

\author{
Sandra Pereira Tosta \\ Pontifícia Universidade Católica de Minas Gerais \\ Andréa Pinheiro Tomaz Carvalho \\ Secretaria de Educação - Contagem - Minas Gerais
}

\section{Resumo}

Este artigo objetivou conhecer e interpretar a construção identitária de adolescentes a partir dos gostos, estilos, comportamentos e experiência escolar, percebidos nos modos como um grupo de alunos do terceiro ciclo se apropria de significados, usa-os e atribui significados aos tempos e espaços externos à sala de aula. Tratou-se de um estudo qualitativo realizado numa escola da rede municipal de Contagem - MG, nos anos de 2007 e 2008, com o uso de questionário, depoimentos e observação sistemática das rotinas escolares. Os resultados mostram que, para além do espaço canônico da sala de aula, os diversos modos como os adolescentes se expressam em dinâmicas culturais devem ser considerados nas políticas educacionais.

Palavras-chave: Alunos adolescentes. Tempos e espaços escolares. Culturas. Identidades. 


\section{Education and cultural dynamics: appropriation and (re) signification of school spaces by teenagers}

The aim of this article is to identify and interpret the identity construction of adolescents based on tastes, styles, behaviors and school experience, perceived in the ways in which a group of students of the 3rd cycle appropriates, uses, and a confers meaning to times and spaces outside the classroom. This was a qualitative study in a municipal school in Contagem, MG, in 2007 and 2008, using a questionnaire, testimonials and systematic observation of school routines. The results show that, beyond the canonical space of the classroom, the various ways in which adolescents express themselves in cultural dynamics should be considered in education policy.

Keywords: Teenage students. School time and space. Cultures. Identities.

\section{Dinámicas culturales y educación: apropiación y (re) significación de los espacios de la escuela por los adolescentes}

Este artículo tiene como objetivo identificar e interpretar la construcción de la identidad de los adolescentes a partir de los gustos, estilos, comportamientos y experiencia en la escuela, se percibe en las formas en que un grupo de alumnos del $3^{\circ}$ ciclo se apropia, usa y le atribuye significados a los tiempos y espacios fuera del aula. Este fue un estudio cualitativo en una escuela municipal Contagem- MG, en 2007 y 2008, utilizando el cuestionario, testimonios y observación sistemática de las rutinas escolares. Los resultados muestran que, además del espacio canónico de la clase, las diversas formas en que los adolescentes se expresan en las dinámicas culturales deben ser consideradas en la política educativa.

Palabras-clave: Estudiantes adolescentes. Tiempo y espacio escolares. Culturas. Identidades. 


\section{Introdução}

A adolescência e o adolescente que a vivencia no mundo contemporâneo vêm preocupando a sociedade e o Estado por muitas razões: uma delas é o envolvimento cada vez mais cedo em situações de marginalidade, violência, drogas ou gravidez. Esta fase, entendida, geralmente, como uma passagem sempre crítica para a vida adulta, aparece cada vez mais incerta na perspectiva das políticas públicas e de entidades do terceiro setor, bem como dos grupos familiares. "Em linhas gerais, circulam no cotidiano contemporâneo ideias sobre adolescência e juventude que se associam à noção de crise, desordem, irresponsabilidade, enfim, problema social a ser resolvido". (Lyra et al 1980, p. 11)

No caso do Brasil, especificamente, os números tornam este cenário mais problemático ainda: somos um país com $11 \%$ de sua população vivendo a adolescência. Trata-se de um universo estimado por estudos do Fundo das Nações Unidas para a Infância (Unicef) em 21.083.635 milhões de meninas e meninos, que demandam ser vistos por outro olhar, que permita uma nova reflexão para esta fase da vida - reflexão que desloque o discurso de só ver a adolescência como "aborrescência", dirão uns, colocando-a sempre num plano de problemas, para vê-la com uma oportunidade de desenvolvimento. (Unicef, 2011)

Mas será que a adolescência pode ser simplificada e explicada como um período de transição e de crise apenas? O que significa a adolescência e ser adolescente? Esta fase difere da juventude? Em quais aspectos? Para tentar responder a estas indagações, é preciso levar em conta, inicialmente, que a adolescência, como marca do sujeito, é uma construção cultural e datada historicamente. Entretanto, sem fazer um recuo no tempo, vamos nos ater ao tempo presente, buscando uma compreensão sobre o adolescente, em vista das relações que, como aluno, estabelece com a instituição escolar, particularmente na apropriação e usos de seus tempos e espaços externos à sala de aula.

É desta temática, ainda pouco enfocada na literatura sobre adolescentes e escolas, que trataremos neste artigo. Com isto, esperamos contribuir com os estudos sobre educação e escola, trazendo para nossas investigações aspectos pouco vistos ou (des) significados pelas políticas educacionais e sua instituição na concretude e vivência das rotinas escolares.

Apenas de passagem, assinalaremos que, na metade do século $X X$, marcado pela surpreendente evolução tecnológica, pela explosão da cultura de massa e onda de consumismo, a adolescência tornou-se uma questão social relevante, talvez pelo fato de a visibilidade midiática em escala mundial que viabilizou o 
que chamamos de Sociedade em Rede, parafraseando Manuel Castells (1999), revelar suas diferenças a partir de estilos próprios de ser e viver. São sinais diacríticos que marcam fortemente as gerações, parecendo distanciar, cada vez mais e em intervalos menores de tempo, pais de filhos, adultos de crianças, professores de alunos, por exemplo.

Neste contexto, considerando inúmeros dados de pesquisas de que dispomos ${ }^{1}$, um aspecto chama a atenção: o papel da mídia e do consumo na inclusão simbólica dos indivíduos, particularmente de adolescentes e jovens em uma lógica social marcada pela conectividade e interatividade na escola e em outros espaços de socialização e de sociabilidades. Ensaiar e acenar com estas interpretações nos permite refletir mais detidamente sobre o caráter simbólico do consumo. Para isto, nos acercamos dos trabalhos de Mary Douglas e Isherwood (2004) e Appadurai (2010), que argumentam em favor do consumo como uma dimensão importante da vida nas sociedades complexas. Para além da função meramente utilitária - posta e assimilada em discursos mais ligeiros e pecaminosos sobre o papel da mídia, especialmente da publicidade -, os bens carregam significações e atuam como sistemas de comunicação, de trocas, ao gosto do que já havia nos ensinado magistralmente, em tempos anteriores, o antropólogo L. Strauss. Ou seja, o ato de consumir reveste-se de expressão simbólica e são múltiplas as motivações para que este ocorra (Tosta, 2014), como notamos na pesquisa com os adolescentes na escola.

No Brasil, notadamente a partir dos anos 1980, a adolescência esteve no cerne do debate público. A mobilização em torno dos direitos da infância e da adolescência como fase do ciclo da vida que exige cuidados e proteção especiais resultou na elaboração do Estatuto da Criança e do Adolescente (ECA), promulgado por meio da Lei Ordinária Federal de n.o 8.069/90, que dispõe sobre as ações educativas, de proteção ou punição destinadas à criança - a pessoa de até 12 anos incompletos - e ao adolescente, a pessoa entre 12 e 18 anos de idade.

Com a publicação deste documento, crianças e adolescentes passaram a se constituir, legalmente, sujeitos de direitos, fato inédito na história do País, que mobilizou esforços para a criação de políticas para atender esta camada da população. São conquistas sociais que demarcam novas percepções da adolescência e da juventude relativamente aos tempos passados. Khel, citada em Tosta (2005), por exemplo, lembra que, entre as décadas de 1920-1930, no Brasil, pessoas com 20 anos eram consideradas adultas. Já nos dias de hoje, com

1. Investigações realizadas no EDUC - Grupo de Estudos e Pesquisas em Educação e Culturas do PPG Educação - PUC - Minas e o acervo de dissertações e teses. Disponível em: <http://educpucminas.wix. com/educacaoecultura/>. Acesso em: 10 out. 2014 
esta mesma idade, estão em plena juventude, o que sinaliza para a mobilidade e imprecisão de conceitos como esses. Mudanças que dizem de marcações etárias, mas também simbólicas, nos fazem perceber que permanecer jovem é desejo de muitos. Com o auxílio de tecnologias e os avançados e variados produtos de estética, cada vez mais pessoas buscam aparentar menos idade do que aquela que têm.

Porém, à parte os desejos e a busca incessante por uma aparência mais jovial, indefinições quanto aos termos juventude e adolescência persistem, ora se opondo, ora se integrando. Assim, uma primeira indagação que se coloca é saber se tais termos são distintos e, ao mesmo tempo, complementares, a fim de compreendermos quem são estes sujeitos nas escolas. Para tanto, optamos por buscar marcações que podem ser próprias deste tempo de vida, com o objetivo de desenvolver algumas reflexões com e sobre as especificidades da adolescência em sua relação com os tempos e espaços escolares.

\section{Sinalizações possíveis}

Os estudos do Grupo Técnico Cidadania dos Adolescentes², que contou com a participação da organização não governamental (ONG) Ação Educativa ${ }^{3}$, são referências para a busca da caracterização desta ou destas fases do ciclo da vida. Após inúmeras pesquisas, o referido grupo explicou a juventude como uma etapa da vida que comporta a adolescência, mas vai além dos 18 anos legalmente delimitados pelo ECA. A faixa superior aos 18 anos foi definida pelo grupo técnico como juventude: período ainda diferenciado da fase adulta, caracterizado por demandas específicas, exigindo ações que vão além das garantias asseguradas pelo Estatuto da Criança e do Adolescente. 0 grupo considera, ainda, a dimensão de desenvolvimento e preparação; as noções de experimentação e participação na vida social são mais acentuadas pelos jovens, estando estes mais próximos da vida dos adultos, "onde a inserção em diversas esferas da vida social toma um relevo maior, embora vivenciada de um modo singular" (Freitas, 2005, p. 31). Estes fatores constituem as principais marcas que diferenciam a juventude da adolescência.

De todo modo, para efeito legal e amparo, para a inserção dos indivíduos no mundo do trabalho, por exemplo, torna-se imprescindível a definição de faixas

2. Grupo criado pela Unicef com o objetivo de subsidiar a elaboração de propostas de políticas públicas para jovens e adolescentes de baixa renda.

3. A ONG “Ação Educativa” produziu o material "Juventude e Adolescência no Brasil” a partir da participação no Grupo Técnico Cidadania dos Adolescentes criado pelo Unicef. 
etárias. Tanto que, de acordo com a Organização Mundial de Saúde (OMS), o adolescente se situa entre os 10 e 20 anos, com base nas modificações físicas e psíquicas presentes em meninos e meninas desta faixa de idade. Com efeito, a categoria etária para a definição dos termos adolescência e juventude varia não só entre os diversos países, como também no interior destes. Em estudos sobre a adolescência no Brasil, percebe-se certa tendência a considerar a juventude de acordo com a classificação do Instituto Brasileiro de Geografia e Estatística (IBGE), ou seja, os sujeitos situados entre 15 e 24 anos.

0 que se pode inferir de tudo isto é que as questões culturais e subjetivas atinentes à faixa etária impedem uma demarcação rigidamente determinada, mas, para efeitos de abordagem da realidade social, torna-se importante a adoção de uma referência. Assim, com base no ECA e na situação educacional là qual este estudo se destinou), distinguiremos, ao longo deste artigo, a adolescência da juventude, referenciando-nos na fase escolar designada por ciclo da adolescência, conforme especificado pela rede pública do município de Contagem - Região Metropolitana de Belo Horizonte (RMBH), capital de Minas Gerais, Brasil, local onde a pesquisa foi realizada. 0 terceiro ciclo - ciclo da adolescência - compreende a faixa etária de 12 a 15 anos, englobando a antiga 6. ${ }^{a}$, 7. ${ }^{a}$ e $8 .^{a}$ séries do ensino fundamental de oito anos ${ }^{4}$. Reconhecemos, no entanto e empiricamente, que os sujeitos estudantes deste ciclo foram considerados na investigação como adolescentes, sem necessariamente estarem dentro da referida faixa etária designada pela escola, fato que tensiona claramente a própria realidade escolar em suas divisões, seja por série, seja por ciclos.

Por isto mesmo, baseando-nos em concepções antropológicas sobre identidade, não nos fixamos rigidamente nesta questão etária, manipulando-a nas proximidades de 12 a 15 anos, sem, contudo, deixar de relativizar os dados empíricos que informaram que alunos com mais de 15 anos estavam cursando os referidos ciclos da adolescência. Com esta questão teórica e metodológica propiciada pela imersão na realidade escolar, optamos por identificar, na escuta dos meninos e meninas, seu sentimento de pertença e adesão a conteúdos explicitados na relação com seus grupos de pares que, bem sabemos, influenciam diretamente na construção identitária.

Conforme analisado por Guacira Louro (2000), há uma influência dos padrões de beleza nesta identidade ou afirmação da diferença. Considerados culturalmente como onipotentes e desafiadores, os adolescentes trazem em seus corpos marcas desta busca de padrão de beleza, mas também marcas que contrariam

4. Cita-se o ensino fundamental de oito anos porque, a partir de 2006, o ensino fundamental no Brasil passou a ter duração de nove anos, incluindo a obrigatoriedade da entrada nesta modalidade a partir dos 6 anos de idade. 
estas representações. 0 corpo transforma, cresce e carrega características próprias de seus grupos de convivência. Os aspectos biológicos são facilmente identificados durante essa fase, enquanto as características socioculturais variam de acordo com o espaço vivido. Por isso, tinturas de cabelo, anabolizantes, piercings, maquiagens e ainda modificações simbólicas como gestos, olhares, posturas e outras formas de manifestações corporais podem dizer muito sobre suas identidades. 0 corpo comunica-se com o mundo e, assim, ele não é uma configuração apenas biopsíquica e cultural, mas, também, uma linguagem que, associada a outras, quer expressar-se e comunicar-se com o mundo. Pensar com esta lógica de compreensão do corpo como linguagem, nos termos de Baktin (2006), foi bastante profícuo para compreendermos a importância que este corpo revela quando observamos as adolescências e os adolescentes. A partir da observação de como esses corpos adolescentes se movimentavam nos espaços e tempos fora da sala de aula, buscamos refletir sobre como se relacionam, como expressam, produzem significados e se realizam ritualmente nas rotinas escolares, na apropriação e uso destes espaços. (Mclaren, 1991)

Definimos, assim, como foco da pesquisa estudantes pertencentes ao terceiro ciclo de formação humana reconhecendo-os em suas diferenças econômicas, culturais, sociais e subjetivas. Dialogamos com esses estudantes e os observamos, sabendo-se também observadas, durante seis meses, no ano de 2007, em seus trajetos pelos diversos espaços do ambiente escolar externos à sala de aula. Para desenhar em traços gerais um perfil dessa adolescência, foi aplicado um questionário de sondagem socioeconômico e cultural junto aos 203 estudantes matriculados à época da pesquisa; deste total, 194 responderam.

Importante destacar neste artigo que uma primeira pergunta feita foi: "Você se considera adolescente?" A maioria deles (83\%) respondeu afirmativamente, mas sete alunos, todos com 12 anos, afirmaram serem crianças. Uma das garotas acreditava não ser adolescente porque gostava de brincar na rua, de boneca, não gostava de sair e não pensava em namorar. Disse que muitas garotas que antes brincavam com ela já estavam começando a ir para festas, namorar, mas ela não queria isto. Seu desejo era não passar pela fase da adolescência. Diante de falas como estas, é possível reafirmar o quão é controvertido determinar a idade como marca definidora de tempos da vida e que estávamos no caminho mais seguro: a pesquisa seria realizada com sujeitos que se viam como adolescentes, ou seja, 11 sujeitos que se reconheciam como adolescentes e uma aluna que, não obstante não se identificar como adolescente, desempenhou papel importante no curso da pesquisa, como veremos adiante.

Após interpretar os dados que o questionário apresentou, juntamente com os registros de observações realizadas na escola, foi possível identificar nos 
espaços investigados alguns grupos que se uniam por afinidades diversas. Certo mapa começava a se desenhar, e, para sua composição, destacamos doze adolescentes do terceiro ciclo, turno da manhã, selecionados a partir de características que os diferenciavam por suas posturas corporais, linguagens, preferências musicais, estilos de roupa e formas de interagir no espaço escolar. Esses movimentos de adolescentes no ambiente escolar nos fizeram perceber uma pluralidade de expressões culturais convivendo na escola e como estas influenciam na construção da relação estabelecida com e no espaço escolar - um microespaço social constituído por diferentes sujeitos-adolescentes se apropriando e traduzindo, ao seu modo, o macroespaço social.

Neste lugar, meninos e meninas construíam significados comuns e diferentes, revelando como o espaço escolar comporta a diversidade trazida do ambiente externo e reconfigurada no contexto da escola, adquirindo contornos próprios. Assim, os adolescentes observados no interior da escola trazem traços de um contexto mais amplo, formando teias de significados até então desconsideradas ou não percebidas na cultura escolar, como revelam outros estudos. (Lyra et.al, 1980; Calligaris, 2000; Fraga, 2000; Silvares, Schoen-Ferreira, Aznar-Farias, 2003; Freitas, 2004; Tosta, 2005)

Deste modo, ao ouvir os adolescentes, buscamos compreendê-los em sua(s) identidade(s) nos espaços escolares e captar traços culturais comuns entre estes sujeitos. E, sem dúvida, um dos traços marcantes dos adolescentes pesquisados é a atração pelo "ter e mostrar". 0 uso constante de celulares e de aparelhos eletrônicos, comentários sobre corpo, cabelo, tênis e acessórios foram percebidos recorrentemente durante as observações e em conversas com os alunos, confirmando que o adolescente é fortemente atraído pelo consumo.

Conforme explica Tosta (2005), o adolescente sente a necessidade de poder comprar, sair, enfim, fazer tudo o que é proposto principalmente pela mídia ${ }^{5}$ e que the pareça prazeroso. E o desejo de "ter e ser visto" não pode ser determinado ou explicado apenas por um corte de classe e de poder econômico. Em outros termos, a dimensão do consumo passa pelo acesso a um sistema simbólico cujo apelo, mesmo sendo limitado pelo não acesso ou acesso restrito aos bens materiais, é parcialmente resolvido por alternativas como a aquisição de produtos que imitam marcas usadas pelas pessoas com alto poder aquisitivo. No espaço escolar, é comum observar alunos usando tênis ou chuteiras que revelam fidelidade a certas grifes. Também observamos cenas em que se materializa outra forma de satisfação simbólica do consumo: as relações de troca

5. Referimo-nos à mídia em geral, que engloba os chamados meios de comunicação de massa e os meios digitais. 
e de empréstimo, nas quais os alunos usam bonés, blusas de frio e aparelhos eletrônicos uns dos outros, revelando o desejo de ter objetos que, muitas vezes, não podem mesmo comprar.

Em termos de seus usos dos tempos e espaços escolares, os adolescentes observados buscam integrar-se a grupos de pares para conviver, organizandose em torno de certas características e ou interesses comuns. Já sabemos por inúmeros estudos históricos, antropológicos e psicológicos que a inserção dos adolescentes em grupos de referência é base para a formação das identidades. $E$ que, ao mesmo tempo que o grupo é um suporte, ele provoca ansiedade quando se trata da aceitação ou não do adolescente em seu interior. Por isto, o menino ou a menina fazem tudo para ser aceitos pelos pares, sendo reconhecido como um deles. (Freitas, 2004; Freitas, 2005; Reguillo, 2003, Silvares et al, 2003)

Assim sendo, a família, a escola, a mídia e o grupo são os principais espaços de socialização e de sociabilidades, isto é, como mecanismos de aprendizagens de normas e valores. Embora os valores e crenças da família já tenham influenciado o processo de formação da identidade, é na adolescência que o sujeito reestrutura estes valores fazendo projetos de vida a partir das relações e experiências vividas em outros grupos. (Balleiro, 1999)

\section{Os adolescentes da pesquisa: retratos de unidade e diversidade}

A seguir, oferecemos uma breve descrição destes meninos e meninas a partir de alguns dados registrados no questionário e de suas características mais marcantes, notadas no percurso da observação por nós desenvolvida. Apresentamos: Fernanda, Ícaro, Cristina, Lauret, Johnys, João, Juca, Júnior, Layla, Loreny, Lucas e Pedro6.

Fernanda tinha 12 anos e não se considerava, nem queria ser adolescente. Ela gostava de brincar de boneca, de ouvir música do grupo musical Rebeldes $(R D B)^{7}$, gostava de ler e ficar na rua com uma amiga, não pensava ainda em namorar. Em que pese este não reconhecer-se adolescente por parte da aluna, ela manteve-se no grupo de sujeitos que observamos, pois tornara-se uma “informante" privilegiada, nosso "Doc"8, em nossas andanças pela escola. Estava

6. Não é demais dizer que os nomes são fictícios e que as normas do Conselho de Ética na Pesquisa foram rigorosamente seguidas na pesquisa.

7.RBD foi um grupo musical mexicano surgido em 2004, na novela adolescente Rebelde.

8. "Doc", a figura emblemática do informante de William Foot Whyte, em sua exemplar etnografia: Street corner society publicada no Brasil como: Sociedade de esquina: a estrutura social de uma área urbana pobre e degradada. Rio de Janeiro: Jorge Zahar, 2005. 
atenta ao que acontecia e dialogava constantemente conosco. Fernanda ria alto - de longe era possível ouvir sua voz - e, em seus relatos, mostrava admiração por atitudes adolescentes de colegas.

Ícaro, 14 anos, morava com seu pai, sua mãe e um irmão. Estudava muito, frequentava a biblioteca diariamente, gostava de ler, foi campeão de xadrez na escola e em campeonatos externos, gostava de ouvir ópera, músicas clássicas, ir a museus e sonhava em ser famoso. Era um sonhador, e, em nossas diversas conversas, demonstrou lutar por alguns destes sonhos. Outros sonhos, utopia! Tinha vontade de ganhar um "Oscar", mas não sabia cantar; ou um Nobel de Ciências, e estudava muito para isto. Considerava-se "mais ou menos" adolescente e justificou isso pelo fato de ainda não vivenciar a experiência de ficar ou namorar.

Cristina tinha 16 anos e era presidente do grêmio escolar quando iniciamos a pesquisa. Morava com seus pais e irmã de 11 anos, com quem relata não combinar nem um pouco. Embora demonstrasse ser uma pessoa calma, entrou em alguns conflitos na escola com colegas, membros do grêmio e professoras. Ser presidente do grêmio a fez ficar mais "popular" na escola. No decorrer da pesquisa, Cristina saiu do grêmio por conflitos com a sua vice, mas disse que, no próximo ano, quer se candidatar novamente.

Lauret tinha 15 anos e morava com os avós desde pequena; a responsável legal por ela era a tia, que sempre acompanhava sua vida escolar e cobrava muito dela. Lauret mostrava-se bastante comunicativa, conhecia muitas pessoas na escola, circulava pela escola conversando alto pelo pátio; ela era vista, geralmente, no grupo de "zoadores". Ria alto, brincava, gritava, cantava e utilizava aparelhos eletrônicos mais atualizados que os de seus colegas. Não se importava de emprestar esse aparelho - a cada hora o víamos nas mãos de um adolescente diferente. Gostava de sair, passear e ouvir músicas variadas como hip hop, axé, pagode, enfim; como ela mesma dizia, uma "mistureba". Durante a entrevista descobrimos que Lauret era catequista na igreja que frequentava.

Johnys, 16 anos, assumia-se como homossexual; era alegre, gostava de dançar, sair, já frequentava boates, falava alto e, normalmente, era visto com fones de ouvido e o aparelho emprestado por Lauret ou por outras colegas. Johnys usava cabelos estilo chanel, coloridos em tom vermelho, unhas grandes sempre pintadas de esmaltes. Morava com sua mãe e, segundo ele, disfarçava sempre para que ela não percebesse sua opção sexual.

João tinha 17 anos e estudava na escola há, aproximadamente, dois. Antes estudara em uma escola do bairro onde, segundo ele, havia muitas brigas e atos de indisciplina. Morava com sua mãe e irmão mais velho, com quem diz que saía pela rua pichando casas, prédios e monumentos. Considerava a pichação um 
esporte, uma vez que tinha de escalar paredes e muros, uma aventura! Apesar deste gosto pela pichação, João nos disse que não a fazia mais. A escola havia contribuído muito para esta mudança de atitude. Ele tornara-se membro do grêmio após a saída da colega Cristina e era respeitado por muitos na escola, até por estudantes menores. Como membro do grêmio, começou a colocar som no recreio; gostava de dançar e tinha um grupo de dança na escola. João conversava, brincava e zoava com diferentes pessoas, inclusive funcionários.

Juca tinha 16 anos, morava com sua mãe e irmão, namorava com uma menina de uma escola próxima, usava aliança para afirmar esse compromisso, odiava estudar e ler. Gostava mesmo era de futebol e sonhava um dia ser um famoso jogador. Passava pelos espaços da escola cumprimentando as meninas com beijos, abraços, num gesto carinhoso que dizia ser só amizade. Era zoador e desrespeitava muito os prefessores. No final do ano de 2007, quando realizamos a pesquisa de campo, ele foi transferido para o turno da tarde após agredir uma professora.

Júnior parecia tímido: desde o primeiro dia de pesquisa foi visto sentado sozinho no banco mais afastado. Assim passava o recreio, ou sozinho ou com um amigo. 0 máximo que fazia era comprar a merenda vendida no portão. Ele era do interior do Paraná, tinha 14 anos e, embora já estudasse na escola desde os sete anos ainda, mantinha um sotaque característico do Sul. Morava com seus pais e sua irmã mais nova que, também, estudava na escola. Ele a acompanhava no trajeto escolar, mostrando muito zelo e cuidado. Sentiu-se feliz por ser escolhido para o grupo da pesquisa; dizia considerar-se adolescente, mas gostaria de ser mais brincalhão e divertido como os outros, referindo-se aos zoadores. Pretendia fazer prova para a aeronáutica e gostava de música sertaneja.

Layla tinha 13 anos e era considerada pelos professores uma aluna participativa, com valores éticos e morais e um comportamento investigativo e analítico, conforme registrado no diário do conselho de classe. Era tida pelos colegas como crânio-de-ferro (CDF), a pessoa que estuda muito e brinca pouco. Mas não gostava de ser chamada assim. Layla demonstrava ter responsabilidade com os estudos e preocupava-se com o futuro. Destacava-se no esporte, pricipalmente volei e basquete. Sua equipe na escola já havia conquistado alguns campeonatos. Considerava que o volei, além de esporte, era uma forma de extravasar suas insatisfações. Morava com a mãe e a irmã mais nova e disse que brigava muito com as duas. Layla destacou-se também no xadrez, foi campeã mineira e ficou em quarto lugar no campeonato brasileiro. Andava sempre com um grupo de colegas que disse ser suas amigas desde anos anteriores. 0 grupo gostava de se divertir jogando bola na hora do recreio. Riam e brincavam muito, mas não falavam alto, nem costumavam zoar os outros. 
Nossas observações deram conta, também, de Loreny, 14 anos, andando pelo pátio, beijando um, abraçando outro; passava e sumia da nossa vista. Era considerada na escola uma menina linda. Loreny estava sempre trocando de companhia, costumava fazer amizades que duravam dias ou, no máximo, semanas. Ela nos disse ter sido adotada por sua tia desde muito pequena, porque sua mãe não tinha condições de criá-la. Contou-nos muitas histórias um tanto quanto contraditórias sobre sua vida. Deixava transparecer uma expressão triste sempre que falava de si mesma. Criava muitas confusões na escola, principalmente por ficar com garotos dos quais outras meninas gostavam. Uma vez apanhou de Cristina por causa disso. Depois desse episódio, soubemos que Loreny saiu da escola e que sua tia a devolveu para a mãe biológica.

Lucas tinha 12 anos e possuía uma deficiência que comprometia sua visão e locomoção, apresentava também dificuldades na fala. Morava com seus pais, que pareciam ser muito atenciosos. Lucas fazia natação, violão e tapeçaria. Demonstrava ser um adolescente tranquilo, era visto na escola sempre alegre e costumava andar sozinho pelo pátio. Gostava de ouvir axé e dançar. Mas dizia ter vergonha de dançar na escola.

Já Pedro, com 16 anos à época da pesquisa, era marcado pelo estilo Emo9. Seu corpo falava sobre isto. Ele usava lápis preto nos olhos, cabelo com franja caída, piercing no rosto, calça jeans com cinto preto, tênis tipo All Star também preto e unhas pintadas da mesma cor. Quando não estava em aula, costumava ficar sentado ou até mesmo deitado embaixo de uma árvore com seu grupo de amigos. Conhecia muito bem sobre a tribo Emo e falava com desenvoltura sobre preconceitos e respeito à forma de cada um ser. Disse já ter sofrido muita descriminação por ser Emo na rua e na escola, principalmente porque as pessoas costumavam fazer ligação do estilo com homossexualidade. Não se considerava homossexual e nos disse que tivera namoradas, ressalvando não ter preconceito com qualquer forma de amor. Pedro morava com sua mãe, seus pais eram divorciados, mas disse que conviviam muito bem.

\section{A teia de relações construídas com e nos espaços e tempos escolares}

Magnani (1984) aponta a existência de espaços de socialização básica e estável, que estão entre o público e o privado e os designa de "Pedaços".

9. Emo vem do termo emotional hardcore, um estilo de musica dos anos 1980 pertencente ao punk rock caracterizado pela musicalidade melódica. 
McLaren (1991) define quatro estados interativos, por meio dos quais os alunos assumem papéis de acordo com o espaço: "estado de esquina de rua", "estado de estudante", "estado de santidade", "estado de casa". Deste autor, tomamos o "estado de esquina de rua", que tipifica o comportamento do estudante nos espaços onde há mais liberdade e menos vigilância, como na rua, no pátio da escola, no parque, em loja de jogos, dentre outros. Neste estado, segundo o autor, prevalece a espontaneidade, a alegria, o movimento corporal livre, a ludicidade sem demarcações de gestos precisos. Este estado, de acordo com pesquisas do autor em uma escola no Canadá, era percebido em espaços onde as relações não eram mediadas por controles autoritários, assim os estudantes por ele investigados experimentavam diferentes papéis. Do antropólogo Cantor Magnani, assumimos a categoria "pedaços" que nos permitiu, na pesquisa na escola, traduzir, nos tempos e espaços de encontro entre os adolescentes, onde estes podiam explicitar o "estado de esquina de rua".

Observando atentamente os adolescentes nos múltiplos "pedaços" por ele configurados na instituição escolar e no seu entorno, percebemos que o espaço externo à sala de aula era um "pedaço" maior composto por "outros" menores. Em outros termos, os espaços observados durante a pesquisa compunham uma espécie de mosaico que, por sua vez, era justaposto pelos "pedaços" ocupados pelos diversos estudantes adolescentes. E, em cada um destes espaços, meninos e meninas, por meio de suas interações, os (re) significavam a partir da definição de regras construídas na convivência diária. 0 portão de entrada da escola, por exemplo, era lugar da venda de lanches e tornava-se um "pedaço" onde ocorriam práticas de empréstimos de dinheiro. Juca explicou bem esta configuração:

Pesquisadoras (P) - E a merenda no portão, você pega?

Juca - Pego. É bom lá, né? Porque eu não gosto de comprar no colégio aqui não. Sempre que a gente vai lá, a dona Maria lá recebe fiado... Agora aqui também não deixa, aí a gente vai lá e compra da Dona Maria mesmo, né? Lá é melhor!

$P$ - Vocês têm mania de dividir merenda, né?

Juca - É, eu só divido com quem divide comigo. Quem é lá da minha sala. Eu, Marcos, Rogério, os meninos lá. Aí tem aquele negócio: Ah! Pega lá meia. Aí vem o outro: a meadinha, a meadinha...

P - Chama meadinha? Quando vai pedir merenda para o colega fala meadinha e ele já sabe o que é?

Juca - É, aí nós vai pedir, divide com todo mundo. Brinca bastante, assim, né? (entrevista com Juca, 05/06/2007) 
A chamada "meadinha" da merenda demonstrou interações mediadas pelo consumo entre amigos, o brincar e a busca de novos relacionamentos, pois, muitas vezes, compartilhava-se algo para ser aceito entre os colegas.

Uma árvore, plantada no jardim da escola, tornara-se o "pedaço dos Emos". Este grupo, liderado por Pedro, pichou na árvore a seguinte afirmação: Emocore, que tornou-se, a partir da constante presença dos adolescentes, um espaço tacitamente reservado para eles - lugar onde não eram incomodados pelos zoadores, que costumam reagir com preconceito às escolhas do grupo.

No banheiro feminino as adolescentes se comunicavam: com o próprio corpo visto no espelho, conversando com uma ou mais colegas, e por meio de recados ou pichações deixadas nas paredes. Os meninos, algumas vezes, também entravam neste banheiro para se olharem no espelho, já que em seu banheiro não havia este objeto. Trata-se de fato merecedor de registro, uma vez que os garotos de hoje se preocupam muito com a aparência em geral e, particularmente, com o cabelo, como mostram algumas pesquisas, ou seja, a vaidade deixou de ser uma prerrogativa das meninas. É o que revelam, por exemplo, vídeos produzidos pelo canal de TV-MTV, a partir dos "Dossiês da juventude brasileira". Estes dossiês sistematizam em linguagem audiovisual pesquisas qualitativas e quantitativas periodicamente feitas junto a jovens de todo o País ${ }^{10}$. Com efeito, pela escola circulavam diferentes estilos de cabelo: os penteados predominantes eram o moicano e o arrepiado com gel, para aqueles que não faziam uso do boné. Já nos banheiros masculinos as pichações não eram recados, mas sim expressões artísticas ou de depredação do ambiente.

Bancos podiam ser vistos por todo o espaço escolar: próximos à biblioteca, em frente à rua e no pátio coberto. Pelas observações, concluímos que, para cada um deles, havia diferentes significados. Bancos convertidos em "pedaços", os espaços preferidos dos adolescentes. Os que estavam mais próximos à porta do ginásio eram constantemente ocupados, mas a maioria dos alunos que os frequentava era para brincar, ouvir música, sentar um no colo do outro, enfim zoar, zoar. Até que descobrimos que estes bancos eram chamados pelos adolescentes de "banquinho da amizade". Um dia observamos Layla e suas amigas sentadas num dos "bancos da amizade". Riam, brincavam, sentavam no colo umas das outras. Em uma cadeira próxima dali sentaram três garotas, uma no colo da outra. Um garoto chegou por trás e levantou a cadeira. As meninas pularam e a cadeira foi jogada para o lado. Um funcionário pegou a cadeira, levando-a embora.

10. “Dossiê Universo Jovem", Disponível em: http://vaivirarmar.wordpress.com/2011/01/17/dossieuniverso-jovem-mtv-5-o-agora-ja-foi/. Acesso em: 10 out. 2014 
A retirada dessa cadeira pelo funcionário foi percebida por nós como uma forma de coibir o ato visto como indisciplina, dado que, naquela situação, a cadeira era vista como seu objeto. Em outros termos, era mais fácil retirar o objeto supostamente motivador da indisciplina do que conversar sobre a questão. Mas percebemos, também, que tal postura não impediu os adolescentes de continuarem zoando: as simulações de relação sexual e de troca de afetos eram constantes neste banco onde João costuma brincar e se divertir muito. Já nos bancos mais afastados, não havia muita zoação. Quando o tempo estava frio, muitos alunos gostavam de usá-los para se esquentar, pois ficavam bem expostos ao sol.

Esta teia de relações se estabelecia não só entre sujeitos, mas entre estes e o espaço e seus pedaços. Para mostrar a utilização dos espaços pelos adolescentes, segue a representação:

Figura 1: Mapa dos espaços escolares - 1

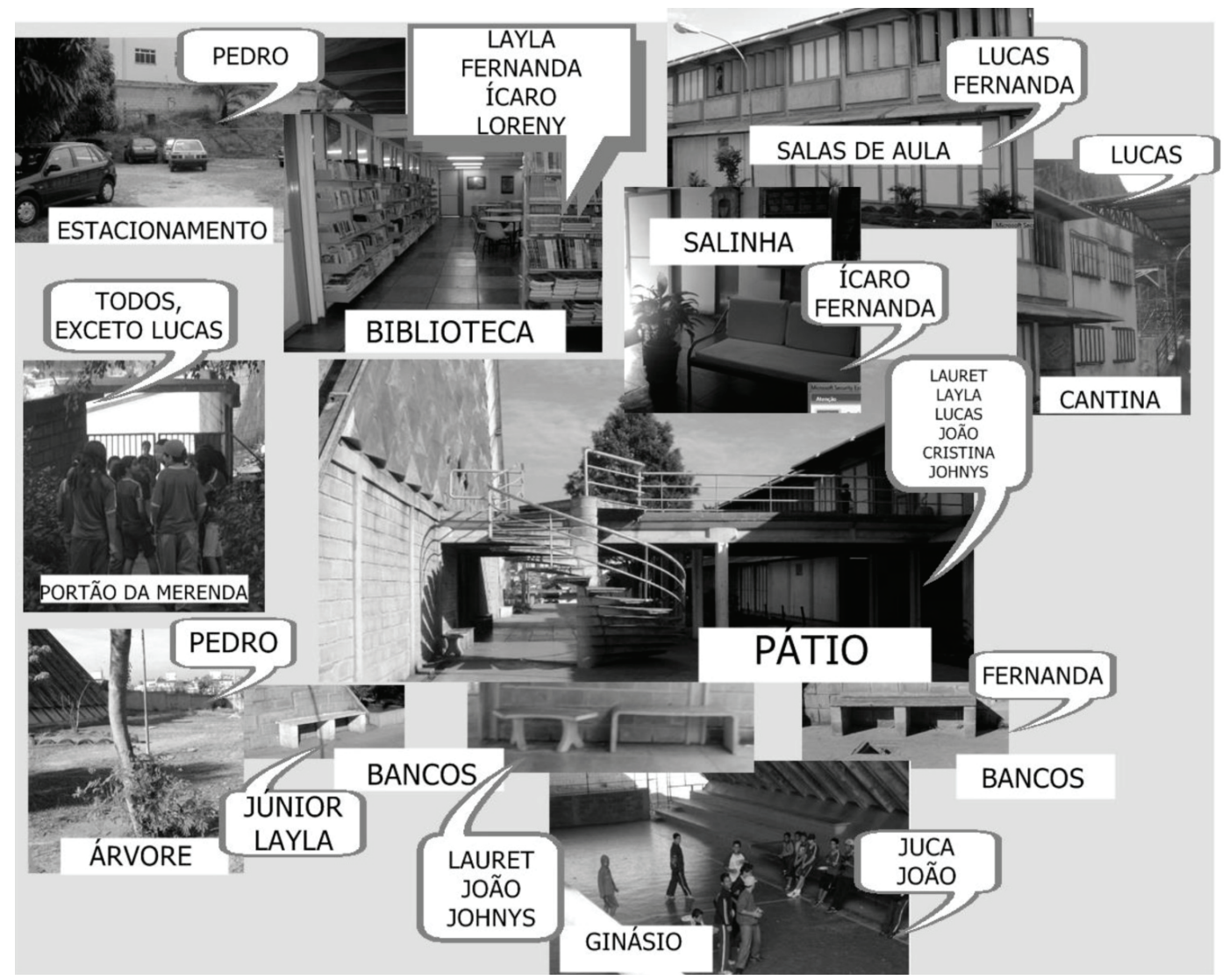

Fonte: arquivo das autoras 
0 retângulo maior representa o espaço escolar destinado aos adolescentes; e os ícones dentro deste, os pedaços dos adolescentes. Nos retângulos externos especificamos os sujeitos que se apropriam destes pedaços, lembrando que, embora se apropriassem do mesmo espaço, isto não significava que se relacionassem entre si. Às vezes, circular por eles significava isolar-se. Outros elegiam lugares isolados dentro ou fora do prédio para apropriar-se deles. E, ainda, outros se apropriavam de lugares centrais. Em resumo, os alunos podiam apropriar-se de espaços em tempos diferentes com finalidades também diferentes. Os retângulos internos representam estes diferentes espaços, em que alguns são externos e outros são intermediários.

Na representação seguinte a relação com espaços mais amplos:

Figura 2: Mapa dos espaços escolares - 2

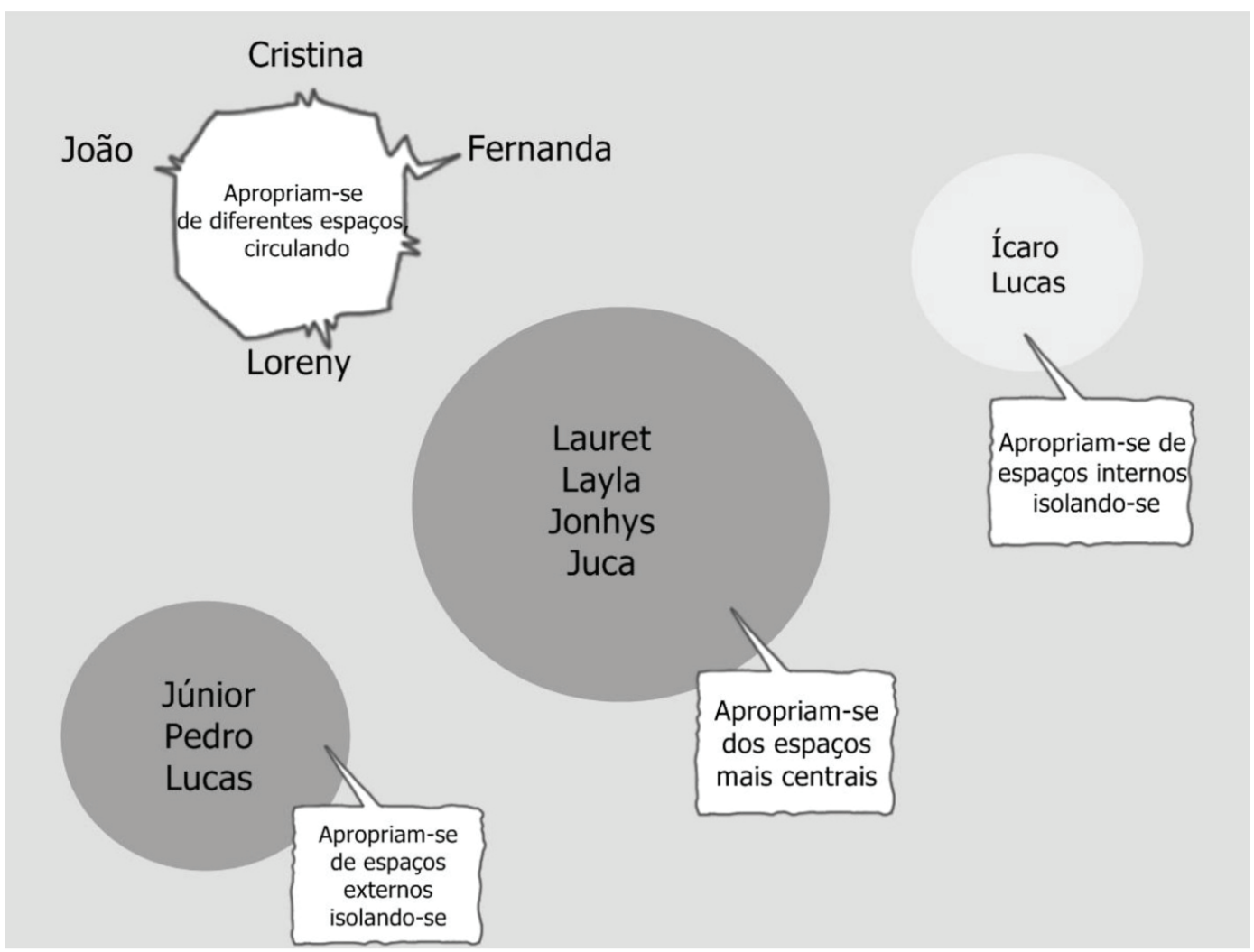

Fonte: arquivo das autoras 
0 retângulo maior representa, como o mapa 1, os espaços destinados aos adolescentes. Os círculos internos significam: espaços externos ao prédio mais centrais, espaços internos do prédio escolar e espaços determinados no espaço externo ao prédio escolar. Os nomes indicam como cada um dos 12 sujeitos apropriava-se destes espaços. Os balões são autoexplicativos.

A partir destas análises, foi possível identificar e tecer algumas interpretações sobre os pedaços tal como apropriados e usados pelos adolescentes da escola pesquisada. Eles se identificavam com estes espaços de acordo com suas relações e sua subjetividade. Lucas, por exemplo, isolava-se tanto nos espaços externos, quanto nos internos. Mas foi nestes últimos que encontrou a convivência com outros adolescentes que ficavam em sala fora do horário de aula. Pedro se isolava do lado de fora, ocupando o espaço perto da árvore ou próximo ao estacionamento junto com seu grupo, onde nem todos afirmavam ser Emos, mas gostavam deste estilo.

Júnior também se reunia com seus amigos no espaço externo do prédio. Costumava comprar a merenda no portão e sentar-se nos bancos mais afastados. Quando estes estavam ocupados por outras pessoas, eles sentavam-se em bancos mais afastados ainda; ou nas grades que cercam parte do jardim. Ícaro, por sua vez, comprava sua merenda no portão e depois ia para a biblioteca ou a salinha. Era raro vê-lo no pátio, a não ser de passagem para a biblioteca.

Muito embora compartilhasse o mesmo espaço com Lauret, Johnys e Juca, Layla não convivia com eles. Ela estava sempre com o mesmo grupo de amigas e costumavam jogar vôlei ou conversar. Johnys, geralmente com fones no ouvido, circulava com mais frequência pelos espaços centrais, dançando, cantando ou conversando nos bancos. Lauret costumava ficar nos bancos próximos à quadra quando estavam zoando; ou nos bancos um pouco mais afastados quando estavam conversando. Diversas vezes a observamos ouvindo música.

Juca também ocupava os espaços mais centrais. E, mesmo ficando muito enturmado com os ditos zoadores, não costumava falar alto, nem ficar gozando os colegas. Às vezes entrava para a quadra do ginásio e jogava futebol. Outras vezes circulava e cumprimentava com abraços e beijos algumas garotas que passassem. Loreny circulava rapidamente entre todos os espaços, mas não tinha vínculo com nenhum deles, costumava passar pelos espaços cumprimentando os garotos e sendo cumprimentada por eles, com beijos e abraços.

João, como Loreny, circulava por todos os espaços, zoando, cumprimentando ou conversando com os outros. Cristina caminhava por todos os espaços, mas sempre conversando tranquilamente com suas amigas; outras vezes falando ao celular ou ouvindo música. Fernanda também andava por todos os espaços, sabia de tudo o que estava acontecendo ao seu redor, sempre acompanhada de sua 
amiga Caroline, e não costumava conversar com outras pessoas. Mas conversava muito conosco; sendo ou não instada a falar, mantinha-nos informada dos acontecimentos.

Deste conjunto de registros, afirmamos, então, que os adolescentes criavam estes "pedaços" escolares junto com seu grupo de convivência. Vale lembrar que havia espaços que, embora acessíveis, não eram apropriados pelos adolescentes em geral. Alguns destes espaços, ocupados por estudantes do segundo ciclo, permitiam uma divisão simbólica entre as fases da vida afirmada pelos ciclos. É o caso, por exemplo, da quadra de cima e da guarita. Outros espaços eram apropriados e compartilhados pelos alunos do terceiro ciclo que nele transitavam, destacando aqui os 12 adolescentes pesquisados.

Estes espaços escolares, que são públicos, acabavam sendo particularizados pela presença rotineira e usos dos estudantes. Como analisado por Certeau (1996), o público e o particular são interdependentes. Se os "pedaços" são interpretados por Magnani (1984) como espaços entre o público e o privado, com normas próprias construídas pelos sujeitos que neles convivem, podemos perceber que o macropedaço da escola, formado pelo espaço externo à sala de aula abordado nesta pesquisa, é formado por micropedaços apropriados pelos adolescentes, numa relação de interconexão.

Assim, valendo-nos das argumentações de Canclini (1997) de que as culturas se misturam, criando formas híbridas, neste caso, presentes e vivenciadas no ambiente escolar externo ao espaço/tempo da sala de aula, falaremos antes de um tipo de bricolage ${ }^{11}$, reunindo e enredando em teias os sujeitos adolescentes em suas diversidades de traços familiares, gosto, estilo, comportamento etc.

Observar, conviver, inventariar e interpretar estes tempos e espaços externos à sala de aula permitiu-nos compreender esta adolescência no espaço/tempo atual com um olhar mais sensibilizado e adensado para escrutinar estas interações produzidas nas dinâmicas culturais dos alunos. Pensando com esta realidade é que nos possibilitou conviver com o aluno para além da sala de aula e indagar: "Reorganizar tempos e espaços": esta frase tão repetida no meio educacional, principalmente referindo-se à escola em ciclos, não necessita ser revista? Reorganizar para quê? Para quem? Como? Afinal, acreditamos que uma escola para a adolescência deve ser vista como um todo e não apenas nos metros quadrados de uma sala de aula confinada, quase sempre, em si mesma, indiferente às demandas dos alunos.

Com efeito, podemos afirmar, também, que, de muitos modos, a pesquisa nos propiciou entender a apropriação que os adolescentes fazem dos tempos e espaços escolares externos à sala de aula, determinados e demarcados

11. A bricolage, no sentido levistraussiano, supõe as formas pelas quais objetos e símbolos são retirados de um repertório cultural já existente; rearranjados em outros contextos, passam a comportar outros tantos significados. 
fisicamente pela própria instituição, sem a prévia consulta e participação dos sujeitos da aprendizagem. Dito de outro modo, a arquitetura escolar adquire materialidade e vida pela ação dos alunos, professores, funcionários, familiares e não simplesmente emana de um projeto que se faz, em geral, alheio a estes sujeitos. Pois bem, ao reconhecer esta adolescência lou que adolescências são estas), poderemos contribuir para redimensionar a percepção de tempos e espaços escolares e atinar para uma instituição mais sintonizada com o tempo presente.

Este é um grande desafio, sem dúvida, mas que interpela a realidade escolar posto que hoje está relacionado à necessidade de garantir uma instituição onde os sujeitos adolescentes sejam vistos e valorizados em seus modos de ser, de pensar e agir; em suas culturas. Sem esquecer, contudo, que a escola é lugar onde a aprendizagem, como um direito de meninos e meninas, aconteça. Reconhecendo, ainda, que conhecimentos ocorrem fora do espaço canônico da sala de aula, ultrapassando essas fronteiras, meninos e meninas aprendem e ensinam nas relações que tecem com e em outros em tempos e espaços de forma mais livre e criativa. Trata-se de desafio que demanda planejar e efetivar uma instituição em que as características e dinâmicas culturais dos sujeitos adolescentes sejam vistas, compreendidas e respeitadas em suas possibilidades de cooperação e de participação nos projetos pedagógicos, para, assim, viabilizar a construção de uma escola para as adolescências, na qual consigamos mesclar conhecimentos socialmente construídos em tempos e espaços, onde se permita ser e viver plenamente, e no tempo presente, este ciclo da vida, que é de aprendizados e de experiências criativas. Uma escola que traduza a dimensão da qual é portadora: de culturas com cores locais que se mesclam às cores institucionais em sua feitura cotidiana. (Rocha; Tosta, 2013)

Como afirma o Unicef (2011): em meio às políticas públicas, a política educacional só torna esta escola possível, com escala e sustentabilidade para todos os adolescentes. E também com projetos pedagógicos desenhados contemplando as especificidades dessa fase da vida e as diferentes condições de se viverem as diversas adolescências que hoje temos no Brasil.

\section{Referências}

ABRAMO, Helena Weber; BRANCO, Pedro Paulo (Orgs). Retratos da juventude brasileira: análises de uma pesquisa nacional. São Paulo: Fundação Perseu Abramo, 2005.

APPADURAI, Arjun. A vida social das coisas - as mercadorias sob uma perspectiva cultural. $1^{a}$ reimpres. Niterói: Edit. da UFF, 2010.

DOUGLAS, Mary; ISHERWOOD, Baron. 0 mundo dos bens: para uma antropologia do 
consumo. Rio de Janeiro: Ed. UFRJ, 2004.

BAKHTIN, Michael. Marxismo e filosofia da linguagem. 12. ed. São Paulo: Hucitec, 2006. BALLEIRO, Maria Clarice. Sexualidade do adolescente: fundamentos para uma ação educativa. Salvador: Fundação Odebrecht, Belo Horizonte: Secretaria de Estado da Educação e Secretaria de Estado da Saúde de Minas Gerais, 1999.

CALLIGARIS, Contardo. A adolescência. São Paulo: Publifolha, 2000.

CANCLINI, Néstor García. Culturas híbridas - estratégias para entrar e sair da modernidade. Trad. de Ana Regina Lessa e Heloísa Pezza Cintrão. São Paulo: EDUSP, 1997.

CASTELLS, Manuel. A sociedade em rede. v.1, São Paulo: Paz e Terra, 1999.

CERTEAU, Michel de; GIARD, Luce; MAYOL, Pierre. A invenção do cotidiano: morar, cozinhar. vol. 2.5 ed. Petrópolis, RJ: Vozes, 1996.

CONTAGEM. Secretaria Municipal de Educação e Cultura. Referencial para a construção da proposta curricular do 3. ${ }^{\circ}$ ciclo de formação de Contagem: SEDUC, 2003.

ESTATUTO DA CRIANÇA E DO ADOLESCENTE: Lei n. ${ }^{0}$ 8.069, de 13-07-1990: Constituição e legislação relacionada. São Paulo: Cortez, 1991.

FRAGA, Alex Branco. Corpo, identidade e bom-mocismo - cotidiano de uma adolescência bem comportada. Belo Horizonte: Autêntica, 2000.

FREITAS, Letícia. Cá entre nós! Deixa que eu seja eu: um estudo de caso sobre usos que alunos do Colégio Imaculada Conceição - Montes Claros - MG, fazem do uniforme escolar. 2004. Dissertação (Mestrado em Educação) Programa de Pós- graduação em Educação. PUC - Minas, 2004.

FREITAS, Maria Virginia de (Org.). Juventude e adolescência no Brasil: referências conceituais. São Paulo: Ação Educativa, 2005.

LDBN - Lei de Diretrizes e Bases Da Educação Nacional: Lei n. ${ }^{0} 9.394$, de 1996, que estabelece as diretrizes e bases da educação nacional: e legislação correlatada. 2 ed. Brasília: Câmara dos Deputados, coordenação de publicações, 2001.

LYRA, Jorge; MEDRADO, Benedito; NASCIMENTO, Pedro; GALINDO, Dolores; MORAES, Maristela; PEDROSA, Claudio. "A gente não pode fazer nada, só podemos decidir sabor de sorvete". Adolescentes: de sujeito de necessidades a um sujeito de direitos. In: GUSMÃO, Neusa Maria Mendes de; SILVA, Vanda. Educação, adolescências e culturas juvenis. Cadernos do CEDES. vol.1, n. 1. São Paulo: Cortez; Campinas: CEDES, 1980. pp. 09-21.

LOURO, Guacira Lopes. Corpo, escola e identidade. Revista Educação e Realidade. Jul/ Dez, 2000, pp 59-75.

MCLAREN, Peter. Rituais na escola: em direção a uma economia política de símbolos e gestos na educação. Petrópolis: Vozes, 1991.

MAGNANI, José Guilherme Cantor. Festa no pedaço: cultura popular e lazer na cidade. São Paulo: Brasiliense, 1984. 
PREFEITURA MUNICIPAL DE CONTAGEM. Ciclo de Formação Humana. Contagem; MG: 2003.

REGUILLO, Rossana. Las culturas juveniles: um campo de estúdio, breve agenda para la discusión. Revista Brasileira de Educação. N. ${ }^{\circ}$ 23. pp. 103-118, Maio. jun. jul. ago. 2003 ROCHA, Gilmar; TOSTA, Sandra de Fátima Pereira. Antropologia \& Educação. 2. ed. Belo Horizonte: Autêntica, 2013.

SILVARES, Edwiges Ferreira de Mattos; SCHOEN-FERREIRA, Teresa Helena; AZNARFARIAS Maria. A construção da identidade em adolescentes: um estudo exploratório. Estudos de Psicologia 2003, 8(1), pp. 107-115.

UNICEF. $O$ direito de ser adolescente: oportunidade para reduzir vulnerabilidades e superar desigualdades. Fundo das Nações Unidas para a Infância. Brasília, DF: Unicef, 2011.

TOSTA, Sandra de Fátima Pereira. Sociabilidades contemporâneas: jovens nas escolas. In: PEIXOTO, Ana Maria Casassanta. e PASSOS, Mauro (Orgs). A escola e seus atores: educação e profissão docente. Belo Horizonte: Autêntica, 2005, pp. 183-197.

TOSTA, Sandra de Fátima Pereira. Culturas juvenis, mídias e suas (des) conexões com a formação e o trabalho docente. Revista entreideias, Salvador, v. 3, n. 1, pp. 147-161, jan./ jun. 2014.

Recebido em junho de 2014

Aprovado em janeiro de 2015

Sandra Pereira Tosta é doutora em antropologia social pela Universidade de São Paulo (USP), professora da Pontifícia Universidade Católica de Minas Gerais (PUC Minas), atuante em seu programa de pós-graduação em Educação. E-mail: sandrađpucminas.br

Andréa Pinheiro Tomaz Carvalho é mestre em educação pela PUC-Minas; atualmente é diretora de um centro municipal de educação infantil em Contagem/MG. E-mail: andreapinheirocarvalhođyahoo.com.br 